IJOT

47,1

Received 8 November 2018 Revised 18 January 2019 Accepted 21 February 2019

\section{A qualitative study of Irish parents' views on hippotherapy, including its influence on their children's home-based occupations}

\author{
Rachel O’Mahony, Emma Connolly and Patrick Hynes \\ Occupational Science and Occupational Therapy, \\ University College Cork, Cork, Ireland
}

\begin{abstract}
Purpose - Hippotherapy is an emerging area of paediatric occupational therapy practice in Ireland. It is a treatment strategy used by specially trained occupational therapy practitioners, physical therapists and speech language pathologists as part of the intervention programme to facilitate functional gains. This paper aims to explore parents' perspectives on children's participation in home-based occupations following hippotherapy treatment.

Design/methodology/approach - Qualitative, semi-structured interviews were conducted with eight participants. Interviews were audio-recorded and transcribed verbatim. In accordance with thematic analysis, line-by-line coding was completed to identify codes. Codes were organised into categories, which were grouped to develop themes.

Findings - Three core themes were identified: lack of knowledge regarding hippotherapy as an occupational therapy intervention; children's increased participation in home-based occupations secondary to improved physical, psychological, communication and social skills; and the unique hippotherapy environment as a motivating factor for children to engage in occupational therapy intervention.

Originality/value - Findings from this study support the growing body of evidence that hippotherapy is an effective means of intervention for increasing physical, psychological, social and communication skills. The participants report positive effects following hippotherapy on their children's participation in homebased occupations. It highlights a link between the unique hippotherapy environment and children's increased engagement in occupational therapy. Given that no published hippotherapy-specific literature related to occupational therapy exists in the Irish context, and given that hippotherapy is an emerging area of practice in Ireland, this paper contributes to the knowledge base.
\end{abstract}

Keywords Hippotherapy, Home-base occupation, Children with disabilities, Occupational therapy Paper type Research paper

(C) Rachel O'Mahony, Emma Connolly and Patrick Hynes. Published in Irish Journal of Occupational Therapy. Published by Emerald Publishing Limited. This article is published under the Creative Commons Attribution (CC BY 4.0) licence. Anyone may reproduce, distribute, translate and create derivative works of this article (for both commercial and non-commercial purposes), subject to full attribution to the original publication and authors. The full terms of this licence may be seen at http:// creativecommons.org/licences/by/4.0/legalcode

This research project was part of the Department of Occupational Science and Occupational Therapy, University College Cork programme of Community-Academic Research Collaboration. The authors wish to thank staff members at the Hippotherapy Clinic who facilitated access to participants, and the participants who took part in this research. 


\section{Introduction}

Hippotherapy is an emerging area of practice in paediatric occupational therapy in Ireland. With the movement of a horse being used as part of an intervention plan (Govender $e t$ al., 2016; Neill, 2018), hippotherapy is used by specially trained occupational therapy practitioners, physical therapists and speech language pathologists [American Hippotherapy Association (AHA), 2016]. Hippotherapy is used to facilitate functional gains for the purposeful manipulation of equine movement to engage neuromotor, sensory and cognitive systems to achieve functional outcomes for individuals with physical, cognitive and neuro-motor deficits (AHA, 2016).

It is useful to distinguish between the different types of therapies that currently exist with the use of the horse to clarify what hippotherapy is and what it is not. Neill (2018) differentiates between hippotherapy and other equine activities including developmental riding therapy, equine-facilitated therapy, psycho-educational vaulting and riding and riding as a sport and skill. Frequently, therapeutic horseback riding (THR) and riding for the disabled are commonly mistaken for hippotherapy. THR requires a certified riding instructor with training in equine management, disabilities and riding instruction. It concentrates on teaching specific riding skills for recreational purposes. In contrast, hippotherapy requires a licensed occupational therapist, physical therapist or a speech language pathologist with specialised training and qualifications (AHA, 2016). In hippotherapy, the child is encouraged to interact and respond to the three-dimensional movement of the horse. In contrast to THR, in hippotherapy, the therapist analyses the movements of the individual on the horse and directs and adjusts the horse's movements according to the individual's needs and abilities (North American Riding for the Handicapped Association, 1998, cited in Sterba, 2007). By incorporating hippotherapy into occupational therapy practice, the ultimate goals are to address the underlying skills required to enhance occupational participation in all areas of an individual's life including work, play, leisure, self-care and social participation (Latella and Langford, 2008).

There is an onus on occupational therapists to research the effectiveness of interventions that they use. Occupational therapists are obligated to prioritise and implement evidencebased practice (Lin et al., 2010; AOTI, 2013; CORU, 2014). In doing so, occupational therapists ensure better outcomes for clients (Shin et al., 2010) and "remain at the cutting edge of practice and education" (Warren et al., 2010, p. 2). However, what is lacking in the published literature is the link between the skills attained in hippotherapy and their transfer to an individual's natural environment following intervention. The challenge of delivering an effective intervention that transfers to the everyday life of children on a long-term basis is a concept highlighted by Heffernan (2017). Furthermore, Cerquozzi et al. (2007) highlight the need for further investigation into the use of hippotherapy and its efficacy in meeting occupational therapy-specific goals. In their statements of best practice, the AHA (2017) advocates that therapy professionals should strive to engage in rigorous research projects to promote the development of an evidence base for the use of hippotherapy. Hills (2018) highlights the need to evidence the effectiveness of the occupational therapy role by being research-informed practitioners. It is incumbent within the profession to research the efficacy of interventions used, such as hippotherapy, and to date, there are no studies on hippotherapy and occupational therapy in the Irish context.

Accordingly, this paper explores the link between Irish children who have attended hippotherapy and their participation in home-based occupations from the parents' perspective. Home-based occupations refer to occupations that children typically do in the home environment, including eating, sleeping, playing and self-care activities such as washing and dressing [World Federation of Occupational Therapists (WFOT), 2010].

Home-based occupations 
IJOT

47,1

\section{Literature review}

The effects of hippotherapy on children with disabilities including Autism Spectrum Disorder (ASD), Cerebral Palsy (CP), Down Syndrome (DS) and learning disabilities formed the majority of findings from the literature, in conjunction with some literature on its use in occupational therapy, and service users and parents' perspectives.

Physical effects

A growing body of evidence exists to support hippotherapy for children who have been diagnosed with ASD, CP and DS (Shurtleff et al., 2009; Taylor et al., 2009; Champagne and Dugas, 2010). Much of the research on hippotherapy indicates positive outcomes in children with these disabilities (Hamill et al., 2007; Shurtleff et al., 2009; Shurtleff and Engsberg, 2010; Park et al., 2014). A meta-analysis undertaken by Zadnikar and Kastrin (2011) indicates that hippotherapy improves postural control and balance in children with CP. Of the 84 children with $\mathrm{CP}$ included across ten studies, therapy was effective with 76 , leading the authors to conclude that hippotherapy can be recommended to improve posture and balance. This is further supported by a systematic review of nine articles by Whalen and Case-Smith (2012), who suggest that hippotherapy had a positive effect on gross motor function in children with CP.

Silkwood-Sherer et al. (2012) conducted research with the aim of assessing the effects of hippotherapy on balance and coordination in children with mild-to-moderate balance issues. Furthermore, they aimed to determine if a correlation exists between changes in balance and functional changes. Findings suggested that hippotherapy was a viable intervention for reducing balance deficits and improving a child's performance of daily life skills where the child experiences mild-to-moderate balance difficulties. So far, studies focussing on the physical benefits of hippotherapy are reported from a physiotherapist perspective. However, it would appear that further research is required to examine the impact of hippotherapy on specific functional gains for children, and not just the physical improvements.

\section{Psychological effects}

Psychological benefits have been recorded in hippotherapy literature with improvements seen in children with a wide range of disabilities including ASD, CP and learning disabilities. Psychological benefits include increased confidence and self-competence (Debuse et al., 2009; Frank et al., 2011; Laiou et al., 2015), motivation (Macauley and Gutierrez, 2004; Llambias et al., 2016; Taylor et al., 2009), participation (Granados and Agis, 2011), increased social interaction and improved mood (Sams et al., 2006; Nimer and Lundahl, 2007) and participation (Granados and Agis, 2011). Similar to studies on the physical benefits of hippotherapy, studies focussing on psychological improvements fail to associate improvements with occupational participation. Furthermore, many of the studies rely on self-reports and observations with limited descriptions of research procedures.

\section{Occupational therapy and hippotherapy}

An individual participates in society through participation in meaningful daily occupations (Law, 2002; Wilcock, 2006; Hocking, 2014), with many of these occupations happening in the home environment. Within paediatric settings, many occupational therapists specialise in facilitating children with special needs to successfully participate in occupations by overcoming deficits or through environmental alterations (Dunn, 2007), and hippotherapy is one of the methods used by occupational therapists.

An exploratory study of the role of occupational therapists in hippotherapy was conducted by Cerquozzi et al. (2007), with results indicating the profession's unique focus 
and goals. Additionally, Cerquozzi et al. (2007) conveyed that occupational therapists reported using hippotherapy to attain typical occupational therapy-specific functional outcomes, including dressing, feeding and engaging in play activities. Furthermore, their study highlights the active role played by occupational therapists in hippotherapy, thus indicating that the profession's expertise and knowledge is valued and beneficial.

There are many gaps to explore in future studies. While it is evident that there is much literature pertaining to the psychological and physical effects of hippotherapy on children with ASD, CP, DS and learning disabilities, so far, studies have used small sample sizes. Many authors advise of the need for large-scale randomised control trials to either refute or confirm current findings of its efficacy as an intervention for children with disabilities (Zadnikar and Kastrin, 2011; Silkwood-Sherer et al., 2012; Whalen and Case-Smith, 2012). In addition, some studies (Sterba, 2007; Zadnikar and Kastrin, 2011; Whalen and Case-Smith, 2012) do not focus on hippotherapy alone and include therapeutic riding techniques, thus limiting a true representation of the effectiveness of hippotherapy. However, given its relatively new introduction to Ireland, conducting a randomised control trial of such a large size was deemed beyond the scope of the current research. Furthermore, what is striking from the literature is the large volume of studies by physical therapists. By contrast, occupational therapy-specific research is limited. As stated earlier, central to occupational therapy is the goal to increase occupational participation for individuals by improving everyday function, but what is lacking in the literature is the link between the skills attained in hippotherapy and their transfer to a child's natural environment. Similar to Laiou et al. (2015), the researchers acknowledge the important role parents play in a child's life, and therefore, it was deemed appropriate to ascertain their perceptive.

\section{Method}

This qualitative study was informed by the theoretical approach of phenomenology. Drawing from a phenomenological approach enabled the researchers to explore the lived experience (Carpenter and Suto, 2008) of parents whose children attended hippotherapy. Semi-structured in-depth interviews were used in this study. Qualitative interviews are recognised as a primary method of data collection in studies where the aim is to explore the lived experience (Carpenter and Suto, 2008). Fontana and Frey (2000) describe the importance of in-depth interviews because they highlight the hows and whats of people's lives.

\section{Participants}

Convenience sampling was used to recruit eight participants through an Irish hippotherapy clinic. Purposive sampling facilitated the recruitment of a small number of participants who would yield the most relevant information about the particular phenomena being studied (Teddie and $\mathrm{Yu}, 2007)$. A staff member at the clinic agreed to act as a gatekeeper. The gatekeeper sent text messages to potential participants detailing the study and inviting them to participate. All participants, who consented to participate in the study, had at least one child who attended hippotherapy. One participant had two children. A second participant had three children. All children were less than 10 years old. The mean age of children was 5.5 years. A wide range of disabilities was represented, including ASD, CP, DS, genetic conditions and developmental coordination disorder (DCD). The male:female ratio of children who attended hippotherapy in this study was 9:2, representing the higher prevalence of disability amongst boys in Ireland (CSO, 2016). Duration of intervention ranged from 3 to 12 months. All participants were fluent English speakers. The children of 
IJOT

47,1

46

participants completed a minimum of eight weekly hippotherapy sessions, with many completing more sessions. Demographic details of the 11 children are listed in Table I.

\section{Data collection}

Semi-structured qualitative interviews were conducted by the first and second authors. A list of sample questions is provided in Appendix 1. The questions provided the researchers with a focus while still allowing a degree of freedom and adaptability to glean information from participants during interviews. Open-ended questions were used to allow participants the opportunity to contribute data uncontaminated by the researchers' interpretations and/ or bias. As each interview progressed, the researchers used more specific probing questions to verify participants' answers and to seek clarification on topics of discussion. Throughout the interview process, participants were encouraged to express opinions honestly and were reassured that there were no right or wrong answers. For participants with more than one child who attended hippotherapy, the researchers conducted separate interviews, i.e. one mother was interviewed first about one child, and then interviewed about her second child who attended hippotherapy. Interviews ranged in length from 30 to $45 \mathrm{~min}$. As per MerleauPonty (1964), cited in Quinny et al. (2016), participants were encouraged to choose interview locations to ensure comfort and convenience and to maximise opportunity for rich data collection. Interviews were voice recorded using digital recorders and transcribed verbatim by the researchers.

\section{Data analysis}

Thematic analysis enabled the researchers to systematically analyse and organise data and identify relevant patterns and themes relating to the research question (Braun and Clarke, 2006). To ensure thorough examination and familiarity of content, the researchers read and re-read the interview transcripts. In accordance with thematic analysis, line-by-line coding was completed to identify codes. Codes were organised into categories, which were then grouped to develop themes. Detailed field notes were kept. As advised by Carpenter and Suto (2008), the researchers discussed and analysed findings.

\section{Rigour and trustworthiness}

The following steps were taken to ensure credibility, transferability, dependability and confirmability. A peer review was conducted with a lecturer at the Department of Occupational Science and Occupational Therapy in University College Cork (UCC). The peer

Table I.

Demographic details of children

\begin{tabular}{llllrl}
\hline Interview & Interviewee & Age of child (years) & Diagnosis & Duration of intervention (months) & Gender \\
\hline 1 & Mother & 9 & DCD & 10 & M \\
2 & Mother & 3 & ASD & 5 & M \\
3 & Mother & 4.5 & CP & 3 & M \\
4 & Mother & 5.5 & ASD & 12 & M \\
5 & Mother & 4.5 & ASD & 4 & M \\
6 & Mother & 5.5 & DS & 3 & M \\
7 & Mother & 8 & Genetic condition & 11 & M \\
8 & Mother & 8 & Genetic condition & 11 & M \\
9 & Mother & 4 & ASD & 4 & F \\
10 & Mother & 3 & ASD & 8 & $\mathrm{~F}$ \\
11 & Mother & 7 & ASD &
\end{tabular}


reviewer was not involved in the research process but reviewed field notes and transcripts analytically to validate or query links established between the data and identified themes, thus contributing towards deeper reflexive analysis and ensuring honesty (Lincoln and Guba, 1985). A thorough account of the research design, with clear and distinct descriptions of context, criteria for participant recruitment, data collection and the process of data analysis is provided to ensure transferability. To ensure dependability, the researchers swapped coded data for re-coding to ensure similar findings. Member checking enabled the researchers to validate interpretations of data and served to strengthen the link between original data and the researcher's interpretations of it (Carpenter and Hammell, 2000; Carpenter and Suto, 2008). Reflective diaries served to determine the researcher's judgements or biases during the research process. The researchers reflected on their own backgrounds and positions to see how they influenced the research process. Being able to explain their decisions helped provide valuable insight as to how the themes were identified (Carpenter and Suto, 2008).

\section{Ethical considerations}

This study received ethical approval from the Social Research Ethics Committee at UCC, Cork, Ireland. Participants were reassured that there were no right or wrong answers and were encouraged to express opinions honestly. Confidentiality and anonymity were assured, and pseudonyms were used in interview transcripts and field notes. All identifiable information was removed. Data storage was considered. All data were password protected on laptops, and data were discussed amongst the researchers and their supervisor only. Informed consent was adhered to. Consent forms were signed by participants who were willing to participate, with the option of withdrawing up to one month following the interview.

\section{Findings}

Following analysis of the data, three themes were identified. These were:

(1) Lack of knowledge regarding hippotherapy;

(2) Increased participation in home-based occupations secondary to physical and psychological improvements and enhanced social and communication skills; and

(3) The unique hippotherapy environment.

\section{Lack of knowledge about hippotherapy as an occupational therapy intervention}

All participants in this study reported a lack of knowledge about hippotherapy and its use as an occupational therapy intervention. Through the following quotes, participants described their confusion about hippotherapy and their drive to search for information on hippotherapy, thus demonstrating their willingness to try different therapies to enhance their children's functional development:

[...] we were looking for an activity for Eamon*, because he is not into group or team sport, he is not a sporty kid, and we were looking for an activity for him to do, but at the same time, something that would benefit him, you know, for his balance and his core strength basically (Interview 1).

I read up her site [.. . ] I never actually heard anything about hippotherapy. I thought it was the funniest name. I thought it was fake, so yeah I just read her site, and looked up the photos, and all that kind of jazz but yeah, I didn’t know what hippotherapy was really (Interview 2). 
He'd [referring to husband] heard another man at work had a son who was also autistic as well. So Jordan* has very much OT issues and social issues as well so we were just wondering, we'd try anything. So we read about [hippotherapy] and we rang them and [... ] she said just come and see (Interview 5).

Increased participation in home-based occupations secondary to physical and psychological improvements and enhanced social and communication skills

All participants in this study highlighted their children's increased participation in occupations in the home environment following hippotherapy. According to the participants, children were increasingly able to participate in occupations of their choice secondary to the following improvements:

- physical improvements;

- psychological improvements; and

- improvements in social and communication skills.

Physical improvements. All participants reported that hippotherapy resulted in positive physical changes in their children. They reported the beneficial physical impacts of hippotherapy on muscle control, coordination, core strength, and balance. Of importance to this study, all participants highlighted how significant physical improvements impacted on their child's ability to participate in occupations typical of the home environment:

[...] within two or three weeks he was a different child, completely different child. He started getting up on all fours to try and crawl around which I never thought he'd do (Interview 7).

Increased physical strength was reported to contribute towards one child's ability to participate for longer in table top activities at home (e.g. colouring):

[...] his core strength really like, it really helped him sit up straight and he was less tired, and I would say that's definitely what happened to Joseph*. Like that's why he used to spend so much time on the floor because it was easier for him to lie on the floor and play rather than try and hold himself up and do bits like this [colouring] at the table (Interview 8).

Participants highlighted their child's ability to mobilise in the home environment, thus facilitating participation:

His core strengthened, he started to get muscles [...] and he isn't bumping into the kitchen counter anymore. He became more spatially aware (Interview 4).

He uses a kind of a walking frame and he's doing an awful lot more of that now and it's great because he can get around faster and he follows us around the house now (Interview 7).

Psychological improvements. All participants commented on the psychological benefits of hippotherapy on their child's emotional sense of well-being. No participant reported negative impacts. Participants highlighted increases in their child's motivation, self-confidence and selfcompetence. Engaging in activities that were seen as mainstream in the home were prominent throughout the data, with participants commenting on the range of new meaningful occupations their children could enjoy both alone and as a family. One participant described how her son's confidence grew, thus enabling him to participate with family:

He wanted to play with his brother. He was doing his usual and was coming back to myself and my husband, and I told him it's ok if he wants to play with him, and he kept getting closer and closer, and eventually he went over and played with him in the sitting room. He never did that before (Interview 2). 
Another participant commented on the changes she observed in her son's level of motivation and interest in occupations at home before and after engaging in hippotherapy:

He wanted to go on the swing [at home] whereas prior to that he'd no interest in the swing so we kind of worked on it bit by bit and then we got a slide. [. . . ] it opened him up to so many activities like the swings and slides (Interview 5).

Participants highlighted the psychological changes hippotherapy brought about in their children's ability to participate in what they considered typical play activities:

She's like a different child. She's into toys, she's into princesses, she has a much bigger variety of interests now (Interview 11).

Jordans* things were cars. Rolling, rolling with cars or spinning a seat and to be honest with you that stopped [after hippotherapy]. Now he likes reading [. . . . Reading to himself or I read to him. He makes a lot of puzzles. He'll do building blocks. He'll do colouring. Before he was like cars, cars, cars [... . whereas now he actually takes the cars and plays with his garage (Interview 5).

Social and communication skills. All participants highlighted the social benefits of hippotherapy for their children and its impact on their ability to engage socially and communicate with family members and friends in the home environment:

[... . he started to make eye contact and then he was starting to use request words because he was talking to the animals in therapy and he kind of brought that home I suppose. He was requesting more at home and looking at us more (Interview 10).

It was a big thing for him to do, because he went from not wanting to do any activities, which engaged other people, you know, ammm, to having to interact with the neighbours every week (Interview 1).

[... ] now she's like a different child. She has more interests. Back then it would have been very one-to-one stuff [games], you know, where she wouldn't have to engage other people with stuff [games] but now she's more open to playing with her brother and sister (Interview 11).

The following participant commented on the impact hippotherapy had on her child's ability to vocalise and its impact on his ability to communicate and interact with her:

We used [to] come home in the car [after hippotherapy] and it'd be all jibber jabber. He'd talk all day as if he's trying to tell you what he's doing (Interview 5).

[... ] even to be able to do jobs [around the house] like [. . . he was pretty much 'you'll do it for me'. But then like after that [hippotherapy] 'get your coat, get your boots, get your hat'. He'd look at you then and then he'd get them (Interview 5).

\section{The unique hippotherapy environment}

All participants discussed the unique setting in which hippotherapy occurs. Participants commented on how the environment differed from a traditional occupational therapy setting. Participants reported their children were more willing to engage in occupational therapy through hippotherapy than they were in a traditional occupational therapy setting. Participants also highlighted that because their children were more willing to engage in therapy in a hippotherapy setting, it resulted in better physical, psychological and social outcomes for their children: 
IJOT

47,1

I thought it was beneficial. I think it's just, you know, you can do physio and you can do OT and they're all one-on-one and they're quite boring for a child, particularly for a child who gets a bit of intervention anyway. Whereas horse riding [hippotherapy] it kind of normalises it I think, you know, he was looking forward to his horse riding lesson as opposed to it being an OT session (Interview 6).

He absolutely loved it. [mimics child] When are we going to horses mam? How many more minutes till we go? (Interview 4).

[... ] because it is a little alternative as well, the fact that it is not clinical, it's not somewhere where he is in a room, or stuck in a room, and there is animals involved, it's magical and I just love that there is animals involved (Interview 2).

\section{Discussion}

This study reveals that from the participants' perspective, there were improvements in their children's communication and social skills, as well as an improvement in their physical and psychological being following hippotherapy, which had a positive impact on their participation in home-based occupations. An increase in their children's occupational participation was observed by all participants within the home environment. Improvements in postural control, balance and coordination may provide children more opportunities to participate in self-care activities and social interactions (Ajzenman et al., 2013). Increased motor abilities in children afford more opportunities to participate in self-care activities such as shoe tying or dressing, leisure activities including cutting or colouring and social interactions with other children (Hilton et al., 2011). Debuse et al. (2009) highlight the link between improved physical function, enhancement in self-esteem and the resulting increase in motivation to attempt new activities. This is further supported by Brown and Dunn (2010), who suggest that active engagement in therapy activities leads to improvements in adaptation and increased willingness to participate in everyday activities. This study supports the theory that hippotherapy is an effective means of intervention for increasing occupational participation through physical changes in muscle strength, coordination and balance. Participants described how increased trunk stability improved a child's ability to sit independently for longer periods, thus allowing him to participate in table-top activities. Furthermore, where balance developed, a child was reported to be able to enjoy using a swing effectively.

Participants also commented on the psychological improvements observed in their children, including increased confidence, self-esteem, motivation and self-competence. These results augment claims that hippotherapy is an effective intervention strategy for emotional and cognitive improvements (Debuse et al., 2009). Meregillano (2004) highlights hippotherapy's multifaceted nature through its impact on all of the body's systems.

A difference was observed by participants in their child's social interaction and communication skills. The hippotherapy centre frequented by participants provided social opportunities to help children enhance social and communication skills. Interaction and engagement with the horse, the occupational therapist and the horse handlers throughout hippotherapy sessions provide opportunities to practice these skills (Hilton et al., 2011). Beck and Meyers (1996) highlight animals as being an important factor for developing social skills in children. Social and verbal interaction in children, they claim, improves as a result of interaction with animals.

All participants reported their lack of knowledge on hippotherapy as an intervention strategy for children with disabilities. Following the literature review conducted by the 
researchers, hippotherapy does not appear to have a consistent definition and is sometimes described in a variety of ways. Owing to hippotherapy being relatively new to Ireland, this lack of clarity requires addressing for the benefit of parents of children with disabilities and health-care professionals. In contrast, in South Africa, Govender et al. (2016) report that awareness amongst occupational therapists of hippotherapy as an intervention is high, with many occupational therapists exposed to it during their studies, outlining that 42 respondents out of 47 indicated that they would consider the use of hippotherapy in the future. This suggests evidence of the profession's belief in its effectiveness as an intervention strategy.

In this study, participants highlighted how the unique hippotherapy environment afforded their children the opportunity to engage in an activity that was perceived as fun and recreational. Environments are the external, physical and social aspects that surround clients while they engage in an occupation (AOTA, 2014). Research indicates that intervention strategies that occur in realistic settings contribute towards increased developmental change in comparison with interventions that occur in contrived, clinic-based settings (Humphrey, 2002; Humphrey and Wakeford, 2006). Participants reported that the fact that therapy sessions were not in "a typical clinical setting" (Interview 1) resulted in their children not associating hippotherapy with any kind of intervention. This is supported by Bachi et al. (2011, p. 302), who state that a "client approaching the stable can hide the fact that he or she is attending therapy". It was also highlighted that the setting in which hippotherapy took place was an integral part of their child's therapeutic experience. Participants expressed how important it was for their child to be having fun, and not resisting therapy. Hippotherapy, as reported by participants, was seen in the eyes of the child as "horse riding" and "an activity for them to have fun". Leisure activities are used in occupational therapy as intervention modalities and as an intervention goal (Tanta and Knox, 2015).

Being in an environment close to nature has its own benefits to therapy, in particular, benefiting human health and well-being (Frumkin, 2001). Participants reported that being in fresh air, having animals around and the rich sensory environment added to the positive impact hippotherapy had on their child. Environmental psychologists have supported this and have shown that exposure to the natural world decreases negative behaviours and states and increases positive ones (Mayer et al., 2009).

The use of an animal in hippotherapy was highlighted as a motivating factor for participants to attend occupational therapy. The use of an animal in therapy offers beneficial and positive impacts as the animal appears to have a natural tendency to create a bond with people (Nimer and Lundahl, 2007). The presence of horses in a therapeutic setting contributes to increased self-confidence and the development of trust (Brandt, 2003). The horse, being a large and powerful animal and being controlled by the rider, contributes to the development of a positive self-image and self-confidence (Atwood Lawrence, 2000). Having a horse involved in therapy sessions added positively to the therapy atmosphere and resulted, as expressed by participants, in the child having trust in the horse and therapist and better engagement in intervention.

\section{Limitations}

Recognising limitations strengthens the validity of research (Carpenter and Suto, 2008). Generalisabilty of this study's findings to a broader population is limited because of the small sample size used. This is especially true as diagnoses and functional ability of all the children varied considerably. 
IJOT

47,1

In addition, Siebes et al. (2002) reported that over half of the studies examining the impact of hippotherapy on children prior to 2001 were of duration shorter than six months. With this in mind, Siebes et al. (2002) deduced that future research should focus on interventions of longer duration. Intervention in research studies from the previous 10 years varies in length from 6 to 16 weeks. Given the participants' perspective on the positive impact of hippotherapy on their children, and that all children were in receipt of intervention for more than three months, the researchers concur with Siebes et al. (2002) that future research should focus on studies with longer duration of intervention, which is likely to supply greater and richer data.

As this was a qualitative piece of research, parents' perspectives were sought. Participants were asked about their children's participation in home occupations as this was the focus of the research. In terms of occupational performance, some interpretation resulted from the themes. Participants were particularly positive in their opinions of hippotherapy; however, to reduce bias, the researchers asked participants if there were any negative aspects to hippotherapy. Participants may not have been fully able to differentiate whether hippotherapy or another therapy was responsible for improvements in their children's participation. However, parents felt it was hippotherapy intervention that caused improvements in participation in home occupations, and for the purpose of this qualitative research, it was valuable to get parents' perspectives.

Finally, children of participants in this study varied in age from three to nine years. During those years, children typically meet a variety of important developmental milestones in social and emotional development, language and communication, cognitive ability and physical development (Case-Smith, 2015). Subsequently, typical developmental changes in the children of the participants who acquired new functional skills that facilitated occupational participation may have occurred in conjunction with the hippotherapy intervention. Also, it is not clear from this study how much prior occupational therapy or other therapeutic intervention that the participants' children had received and whether this may have also had a positive impact on the child's development regarding participation in home-based occupations.

\section{Conclusion}

The aim of this study was to explore parents' perspectives of their children attending hippotherapy intervention and the impact on their children's participation in home-based occupations following the hippotherapy intervention. The findings are positive, in that they indicate that there was improvement in the participation of children in home-based occupations following hippotherapy intervention. However, it may not be surprising that there was a lack of knowledge on what hippotherapy actually was reported by participants. Given that no published hippotherapy-specific literature related to occupational therapy exists in the Irish context, and that it is a new emerging area of occupational therapy practice in Ireland, awareness and knowledge is lacking amongst parents and professionals. Participants' lack of knowledge may stem from the fact that hippotherapy is an emerging area of practice in Ireland. Furthermore, no hippotherapy-specific literature exists to support its use as an intervention in an Irish context. Consequently, further research is needed to raise awareness for parents and children of its use in occupational therapy. In addition, it is recommended that awareness of hippotherapy amongst health-care professionals in Ireland should be investigated to encourage its use as an intervention for children with disabilities. There are many exciting emerging areas of occupational therapy practice on the horizon (Pettigrew, 2010), with hippotherapy potentially being one of them in the Irish context. 
This research focussed on self-reports and observations from the parents' perspective. While functional gains were reported, it is important to note that functional abilities of all children in this study varied considerably. Therefore, more rigorous studies are required to examine functional outcomes. A large-scale randomised control trial using pre- and postoutcome measures would strengthen the evidence for hippotherapy's use in children with physical, cognitive and neurological impairments. Finally, the United Nations Convention on the Rights of the Child emphasises the right of children to voice their opinion in matters affecting their own lives (UNCRC, 1992). Given the child's active involvement in hippotherapy, further research is recommended to examine the child's experience. The child's perspective, coupled with the perspective of the parent, could serve to strengthen its use as an intervention in Ireland. Additionally, exploring occupational therapists' perspectives on hippotherapy would add to the knowledge base.

*Pseudonym Used

\section{References}

Ajzenman, H.F., Standeven, J.W. and Shurtleff, T.L. (2013), "Effect of hippotherapy on motor control, adaptive behaviour, and participation in children with autism spectrum disorder. A pilot study", American Journal of Occupational Therapy, Vol. 67 No. 6, pp. 653-663, available at: http://dx.doi. org/10.5014/ajot.2013.008383.

American Hippotherapy Association (AHA) (2016), Hippotherapy as a Treatment Tool, available at: www.americanhippotherapyassociation.org/ (accessed 17 September 2017).

American Hippotherapy Association (AHA) (2017), Statements of Best Practice for the Use of Hippotherapy by Occupational Therapy, Physical Therapy, and Speech-Language Pathology Professionals, American Hippotherapy Association, available at: www.americanhippotherapyassociation.org/wpcontent/uploads/2015/02/Final-2017-Best-Practice.pdf (accessed 13 July 2018).

American Occupational Therapy Association (AOTA) (2014), "Occupational therapy practice framework: domain and process (3rd ed.)", American Journal of Occupational Therapy, Vol. 68 No. 1, pp. S1-S48, available at: http://dx.doi.org/10.5014/ajot.2014.682006

Association of Occupational Therapists Ireland (AOTI) (2013), "Code of ethics and professional conduct”, available at: www.aoti.ie/attachments/a4e97af7-3a2a-48dd-b3df-c63e1bcaf6e9.PDF (accessed 18 June 2018).

Atwood Lawrence, E. (2000), "The human-horse bond", in Engel, B.T. (Ed.), Therapeutic Riding 2: Strategies for Rehabilitation, Barbara Engel Therapy Services, Durango.

Bachi, K., Terkel, J. and Teichman, M. (2011), "Equine-facilitated psychotherapy for at-risk adolescents: the influence on self-image, self-control and trust", Clinical Child Psychology and Psychiatry, Vol. 17 No. 2, pp. 298-312.

Beck, A.M. and Meyers, N.M. (1996), "Health enhancement and companion animal ownership", Annual Review of Public Health, Vol. 17 No. 1, pp. 247-257.

Braun, V. and Clarke, V. (2006), "Using thematic analysis in psychology", Qualitative Research in Psychology, Vol. 3 No. 2, pp. 77-101.

Brandt, K. (2003), “A language of their own: human-horse communication”, Society and Animals, Vol. 12 No. 4, pp. 299-316.

Brown, N.B. and Dunn, W. (2010), "Relationship between context and sensory processing in children with autism", American Journal of Occupational Therapy, Vol. 64 No. 3, pp. 474-483, doi: 10.5014/ ajot.2010.09077.

Carpenter, C. and Hammell, K.W. (2000), "Evaluating qualitative research", in Hammell, K.W., Carpenter, C. and Dyck, I. (Eds), Using Qualitative Research: A Practical Introduction for Occupational and Physical Therapists, Churchill Livingstone, Edinburgh, pp. 107-119. 
IJOT

47,1

Carpenter, R.L. and Suto, M. (2008), Qualitative Research for Occupational and Physical Therapists: A Practical Guide, Blackwell Publishing, Oxford.

Case-Smith, J. (2015), "Development of childhood occupations”, in Case-Smith, J. and Clifford O’Brien, J. (Eds), Occupational Therapy for Children and Adolescents, 7th ed., Elsevier Mosby, pp. 65-101.

Central Statistics Office (2016), "Small area population statistics", available at: www.cso.ie/en/census/ census2016reports/census2016smallareapopulationstatistics/ (accessed 23 April 2018).

Cerquozzi, C., Cerquozzi, E., Darragh, A. and Kuhaneck, H.M. (2007), "An exploratory survey of occupational therapists' role in hippotherapy", Developmental Disabilities Special Interest Section Quarterly, Vol. 30 No. 3, pp. 1-4.

Champagne, D. and Dugas, C. (2010), "Improving gross motor function and postural control with hippotherapy in children with down syndrome: case reports", Physiotherapy Theory and Practice, Vol. 26 No. 8, pp. 564-571, doi: doi.org/10.3109/09593981003623659.

CORU (2014), "Code of professional conduct and ethics", available at: http://coru.ie/uploads/documents/ OTRB_Code_of_Professional_Conduct_and_Ethics_Bye-Law_25_11_14.pdf (accessed 18 September 2018).

Debuse, D., Gibb, C. and Chandler, C. (2009), "Effects of hippotherapy on people with cerebral palsy from the users' perspective: a qualitative study", Physiotherapy Theory and Practice, Vol. 25 No. 3, pp. 174-192.

Dunn, W. (2007), "Supporting children to participate successfully in everyday life by using sensory process knowledge", Infants and Young Children, Vol. 20 No. 2, pp. 84-101.

Fontana, A. and Frey, J.H. (2000), "The interview: from structured questions to negotiated text", in Denzin, N.K. and Lincoln, Y.S. (Eds), Handbook of Qualitative Research, 2nd ed., Sage, Thousand Oaks, CA, pp. 645-672.

Frank, A., McCloskey, S. and Dole, R.L. (2011), "Effect of hippotherapy on perceived self-competence and participation in a child with cerebral palsy", Paediatric Physical Therapy, Vol. 23 No. 3, pp. 301-308, doi: 10.1097/PEP.0b013e318227caac.

Frumkin, H. (2001), "Beyond toxicity: human health and the natural environment", American Journal of Preventive Medicine, Vol. 20 No. 3, pp. 234-240.

Govender, P., Barlow, C. and Ballim, S. (2016), "Hippotherapy in occupational therapy practice", South African Journal of Occupational Therapy, Vol. 46 No. 2, pp. 31-36, doi: 10.17159/2310-3833/2016/ v46n2a6.

Granados, A.C. and Agis, I.F. (2011), "Why children with special needs feel better with hippotherapy sessions: a conceptual review", The Journal of Alternative and Complementary Medicine, Vol. 17 No. 3, pp. 191-197, doi: 10.1089/acm.2009.0229.

Hamill, D., Washington, K. and White, O. (2007), "The effect of hippotherapy on postural control in sitting for children with cerebral palsy", Physical and Occupational Therapy in Pediatrics, Vol. 27 No. 4, pp. 23-42, doi:Doi.org/10.1080/J006v27n04_03.

Heffernan, K. (2017), "The effect of an equine assisted therapy (EAT) programme on children's occupational performance - a pilot study", Irish Journal of Occupational Therapy, Vol. 45 No. 1, pp. 28-39, available at: https://doi.org/10.1108/IJOT-02-2017-0005.

Hills, C. (2018), "Editorial", Irish Journal of Occupational Therapy, Vol. 46 No. 1, pp. 2-3, available at: https://doi.org/10.1108/IJOT-01-2018-0002.

Hilton, C.L., Zhang, Y., Whilte, M.R., Klohr, C.L. and Constantino, J. (2011), "Motor impairment in sibling pairs concordant and discordant for autism spectrum disorders", Autism, Vol. 16 No. 4, pp. 430-441.

Hocking, C. (2014), "Contribution of occupation to health and wellbeing", in Boyt Schell, B.A., Gillen, G., Scaffa, M.E. and Cohn, E.S. (Eds), Willard and Spackman's Occupational Therapy, 12th ed., Lippincott Williams and Wilkins, Philadelphia, PA, pp. 72-81. 
Humphrey, R. (2002), "Young children's occupations: explicating the dynamics of developmental processes", American Journal of Occupational Therapy, Vol. 56, pp. 171-179.

Humphrey, R. and Wakeford, L. (2006), “An occupation-centred discussion of development and implications for practice", American Journal of Occupational Therapy, Vol. 60, pp. 258-267.

Laiou, A., Christakou, A. and Kaminiotis, V. (2015), "Impacts of hippotherapy on children with cerebral palsy from the parents' perspective: a qualitative research", International Journal of Physiotherapy, Vol. 2 No. 6, pp. 947-957.

Latella, D. and Langford, S. (2008), "Hippotherapy: an effective approach to occupational therapy intervention", Occupational Therapy Practice, Vol. 13 No. 2, pp. 16-20.

Law, M. (2002), "Participation in the occupations of everyday life", The American Journal of Occupational Therapy : Official Publication of the American Occupational Therapy Association, Vol. 56 No. 6, pp. 640-649.

Lin, S.H., Murphy, S.L. and Robinson, J.C. (2010), "Facilitating evidence-based practice: process, strategies and resources", American Journal of Occupational Therapy, Vol. 64 No. 1, pp. 164-171.

Lincoln, Y.S. and Guba, E. (1985), Naturalistic Inquiry, Sage, Beverly Hills CA.

Llambias, C., Magill-Evans, J., Smith, V. and Warren, S. (2016), "Equine-assisted occupational therapy: increasing engagement for children with autism spectrum disorder", American Journal of Occupational Therapy, Vol. 70 No. 6, pp. 653-663.

Macauley, B. and Gutierrez, K. (2004), "The effectiveness of hippotherapy for children with languagelearning disabilities", Communication Disorders Quarterly, Vol. 25 No. 4, pp. 205-228, doi: org/ 10.1177/15257401040250040501.

Mayer, F., Frantz, S., McPherson, C., Bruehlman-Senecal, E. and Dolliver, K. (2009), "Why is nature beneficial? The role of connectedness to nature", Environment and Behaviour, Vol. 41 No. 5, pp. 607-643.

Meregillano, G. (2004), "Hippotherapy", Physical Medicine and Rehabilitation Clinics of North America, Vol. 15 No. 4, pp. 843-854.

Merleau-Ponty, M. (1964), The Primacy of Perception, Northwestern University Press, Chicago, IL.

Neill, S. (2018), "To those who have seen their child healed almost subliminally, the science of therapeutic riding rings true", Horse Healing. Child magazine (undated), available at: www. childmag.co.za/content/horse-healing\#.V2qTvvn171V (accessed 13 July 2018).

Nimer, J. and Lundahl, B. (2007), “Animal-assisted therapy: a meta-analysis”, Anthrozoos, Vol. 20 No. 3, pp. 225-238.

Park, E.S., Rha, D.W., Shin, J.S., Kim, S. and Jung, S. (2014), "Effects of hippotherapy on gross motor function and functional performance of children with cerebral palsy", Yonsei Medical Journal, Vol. 55 No. 6, pp. 1736-1742.

Pettigrew, J. (2010), “Editorial”, Irish Journal of Occupational Therapy, Vol. 38 No. 2, pp. 2-3.

Quinny, L., Dwyer, T. and Chapman, Y. (2016), "Who, where, and how of interviewing peers: implications for a phenomenological study", SAGE Open, pp. 1-10.

Sams, M.J., Fortney, E.V. and Willenbring, S. (2006), "Occupational therapy incorporating animals for children with autism: a pilot investigation", American Journal of Occupational Therapy, Vol. 60 No. 3, pp. 268-274.

Shin, J., Randolph, G.W. and Rauch, S.D. (2010), "Evidence-based medicine in otolaryngology, part 1: the multiple faces of evidence-based medicine", Otolaryngology - Head and Neck Surgery, Vol. 142 No. 5, pp. 637-646, doi: 10.1016/j.otohns.2010.01.018..

Shurtleff, T. and Engsberg, J. (2010), "Changes in trunk and head stability in children with cerebral palsy after hippotherapy: a pilot study", Physical and Occupational Therapy in Paediatrics, Vol. 30 No. 2, pp. 150-163, doi: 10.3109/01942630903517223. 
IJOT

47,1

Shurtleff, T., Standeven, J. and Engsberg, J. (2009), "Changes in dynamic trunk/head stability and functional reach after hippotherapy", Archives of Physical Medicine and Rehabilitation, Vol. 90 No. 7, pp. 1185-1195, doi: 10.1016/j.apmr.2009.01.026.

Siebes, R.C., Wijnroks, L. and Vermeer, A. (2002), "Qualitative analysis of therapeutic motor intervention programs for children with cerebral palsy: an update", Developmental Medicine and Child Neurology, Vol. 44 No. 9, pp. 593-603.

Silkwood-Sherer, D.J., Killian, C.B., Long, T.M. and Martin, K.S. (2012), "Hippotherapy - an intervention to habilitate balance deficits in children with movement disorders: a clinical trial", Physical Therapy, Vol. 92 No. 5, pp. 707-719, doi: 10.2522/ptj.20110081.

Sterba, J.A. (2007), "Does horseback riding therapy or therapist-directed hippotherapy rehabilitate children with cerebral palsy?", Developmental Medicine and Child Neurology, Vol. 49 No. 1, pp. 68-73, doi: 10.1017/S0012162207000175.x/pdf.

Tanta, K.J. and Knox, S.H. (2015), "Play", in Case-Smith, J. and Clifford O’Brien, J. (Eds), Occupational Therapy for Children and Adolescents, 7th ed., Mosby/Elsevier, MD Heights, MO, pp. 483-497.

Taylor, R.R., Kielhofner, G., Smith, C., Butler, S., Cahill, S.M., Ciukaj, M.D. and Gehman, M. (2009), "Volitional change in children with autism: a single-case design study of the impact of hippotherapy on motivation", Occupational Therapy in Mental Health, Vol. 25 No. 2, pp. 192-200.

Teddie, C. and Yu, F. (2007), "Mixed method sampling: a typology with examples", Journal of Mixed Methods Research, Vol. 1 No. 1, pp. 77-100.

United Nations Convention on the Rights of the Child (UNCRC) (1992), "United nations convention on the rights of the child", available at: www.childrensrights.ie/childrens-rights-ireland/unconvention-rights-child (accessed 16 April 2018).

Warren, A., McGowan, P. and Hynes, P. (2010), "Building on our research ethos", Irish Journal of Occupational Therapy, Vol. 38 No. 1, p. 2.

Whalen, C. and Case-Smith, J. (2012), "Therapeutic effects of horseback riding therapy on gross motor function in children with cerebral palsy: a systematic review", Physical and Occupational Therapy in Paediatrics, Vol. 32 No. 3, pp. 229-242, doi: 10.3109/01942638.2011.619251.

Wilcock, A.A. (2006), An Occupational Perspective of Health, 2nd ed., SLACK Incorporated.

World Federation of Occupational Therapists (WFOT) (2010), "Statement on occupational therapy", available at: www.wfot.org/Portals/0/PDF/STATEMENT\%200N\%200CCUPATIONAL\% 20THERAPY\% 20300811.pdf (accessed 2 April 2018).

Zadnikar, M. and Kastrin, A.J. (2011), "Effects of hippotherapy and therapeutic horseback riding on postural control or balance in children with cerebral palsy: a Meta-analysis", Developmental Medicine and Child Neurology, Vol. 53 No. 8, pp. 684-691, doi: 10.1111/j.1469-8749.2011.03951.

\section{Appendix. Sample interview questions}

Semi-Structured Question Guide for interviews with parents whose children completed hippotherapy intervention.

\section{Hippotherapy}

- Tell me about how you came to know about hippotherapy

- What encouraged you to try it as a method of intervention?

- How many sessions of hippotherapy did your child attend?

- Tell me about how s/he felt before/during/after the hippotherapy sessions

- Tell me what the experience of your child attending hippotherapy was like for you 
Other therapy/intervention

- What other services/interventions was your child involved in at the same time?

- How often did your child receive other services/intervention?

- Did you follow a home programme as outlined by another service/therapist at the same time?

- What was different about hippotherapy for your child?

\section{Hippotherapy intervention}

- What difficulties/challenges was your child experiencing prior to hippotherapy and did these change following hippotherapy intervention? If yes, can you describe those changes?

- Describe your child's response to hippotherapy

- Do you think the changes were linked to hippotherapy? If yes, describe how you know.

- Were there any negative aspects to hippotherapy intervention?

\section{Corresponding author}

Rachel O’Mahony can be contacted at: rachelsarahomahony@gmail.com

For instructions on how to order reprints of this article, please visit our website: 